CARPATHIAN JOURNAL OF FOOD SCIENCE AND TECHNOLOGY

journal homepage: http://chimie-biologie.ubm.ro/carpathian_journal/index.html

\title{
PNEUMATIC CONVEYING OF SUGAR: EFFECT ON THE RHEOLOGY OF COOKIE DOUGH
}

\author{
Adriana Pieta ${ }^{1}$, Érika Watanabe ${ }^{2}$, Naimara Vieira do Prado ${ }^{1}$, Vânia de Cássia da Fonseca \\ Burgardt $^{1}$, Alessandra Machado-Lunkes ${ }^{1}$, Alexandre Rodrigo Coelho ${ }^{2}$ * \\ ${ }^{1}$ Department of Food Engineering, Federal University of Technology-Parana, Francisco Beltrao, 85601-970, \\ Parana, Brazil. \\ ${ }^{2}$ Department of Food Technology, Federal University of Technology-Parana, Londrina, 86036-370, Parana, \\ Brazil \\ Corresponding author: Department of Food Technology, Federal University of Technology - Parana, \\ Londrina, Brazil. \\ *arcoelho@utfpr.edu.br
}

https://doi.org/10.34302/crpjfst/2019.11.2.5

\begin{tabular}{ll}
\hline Article history: & ABSTRACT \\
Received: & This study evaluated the impact of the pneumatic conveying system on the \\
$\quad$ 25 November 2018 & white sugar particle size and its effects on the rheological behavior of \\
Accepted: & cookie dough. Sugar samples, blended with soft wheat flour $(1: 2.4 \mathrm{w} / \mathrm{w})$, \\
$\quad$ 5 May 2019 & were analyzed for rheological properties. These blends were used to \\
Keywords: & develop cookie doughs, which were submitted to consistency, stability, and \\
Particle size; & hardness analyses. The pneumatic conveying system reduced the white \\
Water absorption; & sugar particles sizes. Wheat flours blended with sugar after pneumatic \\
Mixolab; & conveying (APC) showed lower water absorption and higher starch \\
Hardness. & retrogradation rates than the samples with sugar before pneumatic \\
& conveying (BPC). For the cookie dough, although the APC sugar resulted \\
& in a harder texture, the condition of sugar did not affect the resistance and \\
& stability. The particle size of white sugar affected water absorption and \\
& starch retrogradation rates of wheat flour and hardness of cookie dough. \\
\hline
\end{tabular}

\section{Introduction}

Sugar and wheat flour are two of the main ingredients used in cookie dough formulations, and, consequently, affect its quality (Manohar and Rao 1997). Starch and proteins present in wheat flour absorb water, forming the gluten, which increases the viscosity of dough (Dhaka and Khatkar, 2013). Sugar affects not only dough viscosity, but also increases starch gelatinization temperature and delays or inhibits gluten development (Pareyt and Delcour, 2008). In the food industry, pneumatic conveying is the best way to move ingredients; however, movement and handling of sugar can increase the proportion of finer particles, due to the breaking of crystals to a greater or lesser extent (Manley 2000).

White sugar particle size has an effect on various rheological characteristics of cookie dough, such as consistency, toughness and apparent viscosity (Manohar and Rao 1997). According to Cauvain and Young (2006), the main influence of white sugar particle size is on the dissolution rate of its crystals in water. Thus, it is of extreme importance to understand the influence of sugar particle size on the rheology of cookie dough to anticipate its behavior during the cookie production stages, as well as its impact on the appearance and texture of final product (Manohar and Rao 
2002). The objective of this study was to investigate the impact of the pneumatic conveying system on the white sugar particle size and its consequent effects on the rheological behavior of cookie dough.

\section{Materials and methods}

\subsection{Materials}

White granulated sugar produced in 2012/2013 harvest was obtained from three different suppliers in the state of São Paulo, Brazil (designated Suppliers A, B, and C). These samples were separated into two groups: sugars $\mathrm{A}, \mathrm{B}$, and $\mathrm{C}$ collected before pneumatic conveying (BPC) and sugars $\mathrm{A}, \mathrm{B}$, and $\mathrm{C}$ collected after pneumatic conveying (APC).

Soft wheat flour was purchased from one supplier in the state of Rio Grande do Sul, Brazil and other ingredients for cookie dough production, such as fat, emulsifier, flavoring, acidifying, baking powder and salt were purchased from suppliers in the state of Santa Catarina, Brazil.

\subsection{Methods}

\subsubsection{Pneumatic conveying system}

The pneumatic conveying system utilized to move and fraction white sugar used a positive dilute phase pneumatic conveying, according to the classification suggested by
Klinzing et al. (2010) and Mills (2004). This system included three air blowers, operating at a pressure range of 0.40 to 0.67 bar and pressure limit at 0.80 bar. The airflow generated by blowers was $16.5 \mathrm{~A} \mathrm{~m} 3 / \mathrm{min}$, with an estimated airspeed of $22.0 \mathrm{~m} / \mathrm{s}$ and conveying flow speed at approximately 11.0 $\mathrm{m} / \mathrm{s}$.

\subsubsection{Determination of particle size distribution of white sugar}

Particle size distribution of BPC and APC white sugar samples was determined with five replications for each sample, following the GS2/9-37 method of International Commission for Uniform Methods of Sugar Analysis (ICUMSA 2007). The average of particle size (millimeters) was calculated by the Rens method (ICUMSA 2007).

\subsubsection{Flour rheological analysis}

Rheological properties of wheat flour (utilized as the control) and the blends (wheat flour + white sugar, 1:2.4 w/w) were analyzed using Mixolab (Chopin, France), according to methods 173 (ICC 2011) and 54-60.01 (AACC 2000). Equipment settings followed recommendations of International Association for Cereal Science and Technology (ICC 2011), as seen in Table 1.

Table 1. Configuration of Mixolab equipment for rheological analysis

\begin{tabular}{|c|c|}
\hline Settings & Values \\
\hline Mix speed & $80 \mathrm{rpm}$ \\
\hline Temperature $1^{\text {st }}$ Phase $(\mathrm{C} 1)$ & $30^{\circ} \mathrm{C}$ \\
\hline Temperature $2^{\text {nd }}$ Phase $(\mathrm{C} 2)$ & $30-60^{\circ} \mathrm{C}$ \\
\hline Temperature $3^{\text {rd }}$ Phase $(\mathrm{C} 3)$ & $60-90^{\circ} \mathrm{C}$ \\
\hline Heating rate & $4^{\circ} \mathrm{C} / \mathrm{min}$ \\
\hline Temperature $4^{\text {th }}$ Phase $(\mathrm{C} 4)$ & $90^{\circ} \mathrm{C}$ \\
\hline Time $4^{\text {th }}$ Phase $(\mathrm{C} 4)$ & $15 \mathrm{~min}$ \\
\hline Temperature $5^{\text {th }}$ Phase $(\mathrm{C} 5)$ & $90-50^{\circ} \mathrm{C}$ \\
\hline Cooling rate & $4^{\circ} \mathrm{C} / \mathrm{min}$ \\
\hline
\end{tabular}


$\mathrm{C} 1$ to $\mathrm{C} 5$ correspond to each peak of a typical curve generated by the equipment

Analyses included water absorption (\%), development and consistency (C1), protein reduction (C2), starch gelatinization (C3), amylase activity (C4), and starch retrogradation (C5). Codes C1 to C5 corresponded to each peak of a typical curve generated by the equipment and the unit used was the newtonmeter (Nm) (Banu et al. 2011; Jia et al. 2011; Mironeasa et al. 2012).

\subsubsection{Cookie dough production}

The cookie dough was prepared using the "cream method" described by Moretto and Fett (1999) and Manley (2000). First, the fat, emulsifier, flavoring, acidifying, baking powder, salt and water were homogenized and then wheat flour, sugar and starch were incorporated. The percentage of ingredients is confidential information of industry.

\subsubsection{Cookie dough consistency and stability}

Analyses of consistency and stability of cookie doughs utilized the MIXOLAB equipment (Chopin, France), according to the method applied to the industrial process (Chopin 2009). For this purpose, $100 \mathrm{~g}$ of cookie dough was submitted to mechanical work at $100 \mathrm{rpm}$, for $10 \mathrm{~min}$ at $30^{\circ} \mathrm{C}$. The torque generated in $\mathrm{C} 1(\mathrm{Nm})$ calculated cookie dough consistency and its stability was determined by the time of permanence in this consistency. The test settings are the same as those described in Table 1 and results were obtained by the average of three replicates.

\subsubsection{Cookie dough texture}

The TAXT plus texture analyzer (Stable Micro Systems, UK) measured the cookie dough hardness (expressed in Newton) using a $6 \mathrm{~mm}(\mathrm{P} / 6)$ cylindrical probe and an accessory (A/DP). Six replicates with $110 \mathrm{~g}$ of dough was evaluated and the test conditions were pre-test speed was $2.0 \mathrm{~mm} / \mathrm{s}$, test speed $3.0 \mathrm{~mm} / \mathrm{s}$, posttest speed $10.0 \mathrm{~mm} / \mathrm{s}$ and distance was $20 \mathrm{~mm}$.

\subsubsection{Statistical Analysis}

Results expressed the mean \pm standard deviation. Statistical analysis of variance and Tukey test $(\mathrm{p}<0.05)$ were performed using Statistica software (version 7.0).

\section{Results and discussions}

Pneumatic conveying had an impact on the distribution of white sugar particle size, reducing significantly the size of all samples, around $23 \%$ (Table 2). Although white sugar particle size from supplier A was smaller $(\mathrm{p}<0.05)$ when compared to suppliers B and C in the BPC condition, after pneumatic conveying, no differences were observed for the three suppliers samples. These results are important for the food industry, which can use raw materials from different suppliers, but need to maintain the same characteristics in the final product.

Bell (2015) relates that in a pneumatic conveying system, the reduction of particle size is typically caused by high-velocity impacts or attrition between particles or between particles and system walls. Reduction on particle sizes increases the dissolution rate of white sugar in water, accelerating the mixing process or dissolution of the ingredients (Oliveira et al. 2007). For cookie production, considering the relationship between the sugar particle sizes and cookie dough baking process, any interference that can cause variations in the sugar particle size will reflect on the dough rheological behavior.

Rheological characteristics of wheat flour blended with sugar samples (Table 3) showed a reduction in water absorption and stability when compared to the control (wheat flour). This result suggests that this reduction is associated with competition between sugar and wheat flour by the available water.

Wheat flour had lower protein reduction (C2) than the blends, indicating an increase in consistency of dough due to the presence of sugar. Starch gelatinization (C3), $\alpha$-amylase 
activity (C4), and starch retrogradation (C5) of the blends were also higher than the control, showing that white sugar reduced dough viscosity and $\alpha$-amylase activity, but increased starch retrogradation.

Table 2. Distribution of white sugar particle size from A, B, and C suppliers, before pneumatic conveying (BPC) and after pneumatic conveying (APC) $)^{1}$

\begin{tabular}{|c|c|c|c|}
\hline \multirow{2}{*}{ Condition of sugar } & \multicolumn{3}{|c|}{ White sugar particle size (mm) } \\
\cline { 2 - 4 } & A supplier & B supplier & C supplier \\
\hline BPC & $0.57 \pm 0.01^{\mathrm{bB}}$ & $0.61 \pm 0.02^{\mathrm{aA}}$ & $0.62 \pm 0.02^{\mathrm{aA}}$ \\
\hline APC & $0.46 \pm 0.04^{\mathrm{cC}}$ & $0.47 \pm 0.02^{\mathrm{cC}}$ & $0.45 \pm 0.05^{\mathrm{cC}}$ \\
\hline
\end{tabular}

${ }^{1}$ Mean values \pm standard deviation of five replicates. Different lowercase letters in the same line and different uppercase letters in the same column are significantly different by Tukey test $(p<$ $0.05)$

Table 3. Analyses of wheat flour blended with white sugar from A, B, and C suppliers before pneumatic conveying (BPC) and after pneumatic conveying (APC) ${ }^{1}$

\begin{tabular}{|l|c|c|c|c|c|c|l|}
\hline \multirow{2}{*}{ Analysis } & \multirow{2}{*}{$\begin{array}{c}\text { Wheat } \\
\text { flour }\end{array}$} & \multicolumn{5}{|c|}{ BPC } \\
\cline { 3 - 8 } & & \multicolumn{5}{|c|}{ Wheat Flour + White sugar } \\
\cline { 3 - 8 } & & Supplier A & Supplier B & Supplier C & Supplier A & Supplier B & Supplier C \\
\hline WA (\%) & $61.70 \pm 0.00$ & $29.50 \pm 0.00$ & $29.50 \pm 0.01$ & $30.0 \pm 0.00$ & $27.40 \pm 0.00$ & $27.40 \pm 0.00$ & $27.40 \pm 0.00$ \\
\hline C1(Nm) & $1.12 \pm 0.01$ & $1.11 \pm 0.01$ & $1.20 \pm 0.06$ & $1.04 \pm 0.08$ & $1.15 \pm 0.06$ & $1.17 \pm 0.08$ & $1.10 \pm 0.02$ \\
\hline Stability & $10.52 \pm 0.23$ & $0.99 \pm 0.15$ & $0.95 \pm 0.07$ & $1.12 \pm 0.20$ & $2.93 \pm 0.58$ & $1.64 \pm 0.19$ & $1.92 \pm 0.32$ \\
\hline C2 (Nm) & $0.47 \pm 0.02$ & $0.74 \pm 0.02$ & $0.78 \pm 0.03$ & $0.71 \pm 0.05$ & $0.71 \pm 0.41$ & $0.88 \pm 0.07$ & $0.88 \pm 0.02$ \\
\hline C3 (Nm) & $1.69 \pm 0.03$ & $0.98 \pm 0.01$ & $0.99 \pm 0.02$ & $0.97 \pm 0.03$ & $0.86 \pm 0.53$ & $1.1 \pm 0.04$ & $1.11 \pm 0.01$ \\
\hline C4 (Nm) & $1.42 \pm 0.04$ & $0.21 \pm 0.01$ & $0.19 \pm 0.01$ & $0.19 \pm 0.00$ & $0.54 \pm 0.54$ & $0.21 \pm 0.01$ & $0.21 \pm 0.01$ \\
\hline C5 (Nm) & $2.06 \pm 0.03$ & $1.81 \pm 0.04$ & $1.87 \pm 0.12$ & $1.83 \pm 0.01$ & $1.84 \pm 0.08$ & $1.46 \pm 0.08$ & $1.60 \pm 0.04$ \\
\hline
\end{tabular}

${ }^{1}$ Mean \pm standard deviation of three replicates. ${ }^{2}$ Values expressed in minutes. WA: water absorption; $\mathrm{C} 1$ : development and consistency; $\mathrm{C} 2$ : protein reduction; C3: starch gelatinization; $\mathrm{C} 4: \alpha$-amylase activity; $\mathrm{C} 5$ : starch retrogradation 
Table 4. Rheological evaluation of wheat flour blended with white sugar based only on sugar condition: before pneumatic conveying (BPC) and after pneumatic conveying (APC)

\begin{tabular}{|c|c|c|c|}
\hline Analysis & Wheat Flour & $\begin{array}{l}\text { Wheat Flour + sugar } \\
\text { (BPC) }^{1}\end{array}$ & $\begin{array}{l}\text { Wheat Flour + sugar } \\
\text { (APC) }{ }^{1}\end{array}$ \\
\hline Water absorption (\%) & $61.70 \pm 0.01^{\mathrm{a}}$ & $29.50 \pm 0.28^{b}$ & $27.40 \pm 0.00^{c}$ \\
\hline C1 (Nm) & $1.12 \pm 0.01^{\mathrm{a}}$ & $1.12 \pm 0.09^{\mathrm{a}}$ & $1.13 \pm 0.06^{\mathrm{a}}$ \\
\hline Stability (min) & $10.52 \pm 0.23^{\mathrm{a}}$ & $1.02 \pm 0.15^{\mathrm{b}}$ & $3.27 \pm 3.89^{\mathrm{b}}$ \\
\hline $\mathrm{C2}(\mathrm{Nm})$ & $0.46 \pm 0.02^{b}$ & $0.74 \pm 0.04^{\mathrm{a}}$ & $0.82 \pm 0.22^{\mathrm{a}}$ \\
\hline C3 (Nm) & $1.69 \pm 0.03^{\mathrm{a}}$ & $0.98 \pm 0.02^{\mathrm{b}}$ & $1.02 \pm 0.29^{b}$ \\
\hline C4 (Nm) & $1.41 \pm 0.04^{\mathrm{a}}$ & $0.19 \pm 0.01^{b}$ & $0.32 \pm 0.31^{b}$ \\
\hline C5 (Nm) & $2.05 \pm 0.03^{\mathrm{a}}$ & $1.83 \pm 0.07^{b}$ & $1.63 \pm 0.18^{c}$ \\
\hline
\end{tabular}

${ }^{1}$ Mean \pm standard deviation of three suppliers. C1: development and consistency; C2: protein reduction; C3: starch gelatinization; C4: $\alpha$-amylase activity; C5: starch retrogradation. Different letters in the same line are significantly different by Tukey test $(p<0.05)$.

Table 5. Effect of white sugar before pneumatic conveying (BPC) and after pneumatic conveying (APC) on the consistency, stability, and hardness of cookie doughs

\begin{tabular}{|c|c|c|c|c|c|}
\hline \multicolumn{2}{|c|}{ Sugar Sample } & $\begin{array}{c}\text { Consistency } \\
(\mathbf{N m}) 1\end{array}$ & $\begin{array}{c}\text { Stability } \\
(\mathbf{m i n}) 1\end{array}$ & $\begin{array}{c}\text { Hardness } \\
(\mathbf{N m}) 2\end{array}$ & Hardness Average \\
\hline \multirow{3}{*}{ BPC } & Supplier A & $1.70 \pm 0.05$ & $9.73 \pm 0.06$ & $1.50 \pm 0.14$ & \\
\cline { 2 - 5 } & Supplier B & $1.72 \pm 0.04$ & $9.69 \pm 0.03$ & $1.26 \pm 0.18$ & \multirow{2}{*}{$1.38 \pm 0.16^{\mathrm{b}}$} \\
\cline { 2 - 5 } & Supplier C & $1.57 \pm 0.07$ & $9.74 \pm 0.02$ & $1.38 \pm 0.18$ & \\
\hline \multirow{3}{*}{ APC } & Supplier A & $1.71 \pm 0.04$ & $9.71 \pm 0.12$ & $1.87 \pm 0.18$ & \multirow{2}{*}{$1.59 \pm 0.28^{\mathrm{a}}$} \\
\cline { 2 - 5 } & Supplier B & $1.71 \pm 0.19$ & $9.69 \pm 0.07$ & $1.51 \pm 0.13$ & \\
\cline { 2 - 5 } & Supplier C & $1.67 \pm 0.17$ & $9.63 \pm 0.03$ & $1.40 \pm 0.28$ & \\
\hline
\end{tabular}

${ }^{1}$ Mean \pm standard deviation of three replicates. ${ }^{2}$ Mean \pm standard deviation of six replicates. Different letters in the same column are significantly different by Tukey test $(p<0.05)$

The conveying system was the only factor that affected rheological properties of blends $(\mathrm{p}<0.05)$. Thus, the Tukey test was applied to compare the averages of suppliers' results and to evaluate the influence of sugar condition (BPC and APC) on the rheological behavior of wheat flour and white sugar blends (Table 4). White sugar promoted a drastic reduction in 
water absorption by wheat flour and the blend containing sugar APC showed the lowest rate of water absorption $(\mathrm{p}<0.05)$. This fact suggests that APC sugar competes for water more effectively than wheat flour, due to the fact that dissolution rate of smaller particles is faster (Cauvain and Young 2006; Oliveira et al. 2007). Results of development and consistency (C1) were the same for the samples and control, indicating that the sugar particle sizes did not affect gluten behavior and dough development. Mixtures containing BPC and APC sugars also had the same stability, but with the shorter time than the control. This fact may be related to the competition between sugar and wheat flour for water molecules.

The BPC and APC sugar blends showed no differences for $\mathrm{C} 2, \mathrm{C} 3$, and $\mathrm{C} 4$ parameters, suggesting that sugar particle size did not influence protein weakening, starch gelatinization and $\alpha$-amylase activity of blends. On the other hand, the addition of these sugars affected the rheological behavior of wheat flour, reducing its starch gelatinization and $\alpha$ amylase activity. An increase in the degree of starch gelatinization promotes a decrease in viscosity of blends (Pareyt et al. 2009). According to Champ (1992), much of wheat flour starch is encapsulated by a protein matrix that restricts the $\alpha$-amylase activity. However, when flour interacts with water and is subjected to mechanical work and heating, this enzymes act on starches, and reduce the viscosity of the mixture.

Analysis of starch retrogradation (C5) differed for blends and control $(\mathrm{p}<0.05)$, with the highest value for control $(2.05 \mathrm{Nm})$ and the lowest for APC sugar blend $(1.63 \mathrm{Nm})$. In this case, not only the presence of white sugar but also the size of its particles influenced the consistency of mixture during the cooling process.

The BPC or APC white sugar condition did not affect consistency and stability of cookie dough; however, APC white sugar resulted in a harder texture of cookie dough (Table 5). The greater availability of this sugar to interact with other cookie dough ingredients (due to its small particle size) may be responsible for this fact, contributing to the structure of dough and, consequently, making it harder. For supplier factor, cookie dough made with white sugar from A supplier was significantly harder than those from B and C suppliers. This result can be explained by smaller particle size of white sugar from supplier A before submitting to the pneumatic conveying system, as seen in Table 2.

Cookie dough rheological analysis showed that sugar particle size did not influence their consistency and stability. These results are in accordance with those found for wheat flour blended with white sugar, showed in Table 4, which demonstrated that only addition of white sugar interfered in dough development $(\mathrm{p}<0.05)$.

\section{Conclusions}

White sugar submitted to the pneumatic conveying system had a reduction in particle size. The small particle size of sugar reduced water absorption and increased starch retrogradation rate of blends and resulted in a harder texture of cookie dough. Finally, although pneumatic conveying system promotes a reduction in the particle size of sugar, industries may continue to use this mechanism to transport sugar during the cookie manufacturing process, and further research on the effect of sugar particle size on cookie hardness is suggested.

\section{References}

AACC 54-60.01 (2000). Determination of Rheological Behavior as a Function of Mixing and Temperature Increase in Wheat Flour and Whole Wheat Meal by Mixolab. Approved Methods of Analysis (10th ed.) St. Paul.

Banu, I., Stoenescu, G., Ionescu, V., Aprodu, I. (2011). Estimation of the baking quality of wheat flours based on rheological parameters of the mixolab curve. 
Czechoslovak Journal of Food Science, 29, 35-44.

Bell, J.M. (2015). Pneumatically conveying fragile materials without particle degradation. PBE. May-2015, 37-44. Available on: Pneumatically-conveyingfragile-materials-without-particledegradation.pdf. Accessed in March 31, 2018.

Cauvain, S.P., \& Young, L.S. (2006). Baked products: science, technology and practice. Oxford, UK, Blackwell Publishing Ltd.

Champ, M. (1992). Determination of resistant starch in foods and food products: interlaboratory study. European Journal Clinical Nutrition, 46(2), 51-62.

Chopin. (2009). Mixolab Applications Handbook: rheological and enzymatic analysis. Villeneuve la Garenne: Chopin Technologies.

Dhaka, V., Khatkar, B.S. (2013). Mixolab Thermomechanical characteristics of dough and bread making quality of Indian wheat varieties. Quality Assurance and Safety of Crops \& Foods, 5(4), 311-23.

ICC 173 (International Association for Cereal Science and Technology) (2011). Whole Meal and Flour from T. aestivum Determination of Rheological Behaviour as a Function of Mixing and Temperature Increase, Vienna.

ICUMSA (International Commission for Uniform Methods of Sugar Analysis) (2007). Methods Book - Method GS2/9-37. The determination of the particle size distribution of white sugar and plantation white sugars by sieving. Berlin, Germany.

Jia, C., Huang, W., Abdel-Samie, M.A.S., Huang, G.M., Guangwei, H. (2011). Dough rheological, mixolab mixing, and nutricional characteristics of almond cookies with and whithout xylanase. Jornal of Food Engeneering, 105(2), 227-32.
Klinzing, G.E., Rizk, F., Marcus, R., \& Leung, L.S. (2010). Pneumatic conveying of solids: a theoretical and practica. New York, Springer Dordrecht Heidelberg London.

Manley, D. (2000). Technology of biscuits, crackers and cookies (4th ed.). Cambridge, England: Woodhead Publishing Limited.

Manohar, R.S., Rao, P.H. (1997). Effect of sugars on the rheological characteristics of biscuit dough and quality of biscuits. Journal of the Science of Food and Agriculture, 75(3), 383-90.

Manohar, R.S., Rao, P.H. (2002). Interrelationship between rheological characteristics of dough and quality of biscuits; use of elastic recovery of dough to predict biscuit quality. Food Research International, 35(9), 807-13.

Mills, D. (2004). Pneumatic conveying design guide (2nd ed.) Oxford: Elsevier Butterworth-Heinemann.

Mironeasa, S., Codina, G.G., Mironeasa, C. (2012). The effects of wheat flour substituition with grape seed flour on de rheological parameters of the dough assessed by mixolab. Journal of Texture Studies, 43(1), 40-8.

Moretto, E., Fett, R. (1999). Processamento e análise de biscoitos. São Paulo: Varela.

Oliveira, D.T., Esquiaveto, M.M.M., Silva Júnior, J.F. (2007). Sugar specification parameters and their impact on the food industry. Food Science and Technology, 27, 99-102.

Pareyt, B., Delcour, J.A. (2008). The role of wheat flour constituents, sugar, and fat in low moisture cereal based products: a review on sugar-snap cookie. Critical Reviews in Food Science and Nutrition, 48(9), 824-39.

Pareyt, B., Talhaoui, F., Kerckhofs, G., Brijs, K., Goesaert, H., Wevers, M., Delcour, J. (2009). A. The role of sugar and fat in 
sugar-snap cookies: structural and textural properties. Journal of Food Engineering, 90(3), 400-8.

\section{Acknowledgment}

The authors would like to thank the Brazilian cookie manufacturer for giving us the opportunity to develop the research; Granolab from Brazil for the flour and cookie dough rheological analyses; and finally, Extralab for the texture analysis. 